\title{
O PACTO PELO ENSINO MÉDIO: REFLEXÕES (PREGRESSAS) SOBRE A EDUCAÇÃO CIENTÍFICA
}

\author{
Marise Nogueira RAMOS ${ }^{\mathbf{1}}$ \\ Universidade Federal Fluminense-UFF/RJ \\ ramosmn@gmail.com
}

Resumo: Popularizar a educação científica na escola (concepção não hegemônica), visando à melhoria da qualidade da educação no ensino médio, como proposição deliberada pela Diretoria de Ensino Médio da Secretaria de Educação Média e Tecnológica do MEC nos anos de 2003 e 2004, é o objetivo do artigo, fundamentado em Ramos (2012; 2011; 2002 e 2003), Vigostsky (1989) e Marandino (2003). O resultado aponta que a proposta não avançou como política pública estruturante. Mediante as DCNEM atuais e anseios do Pacto Nacional pelo Ensino Médio, tenta-se fazer sobreviver a importância desse debate presente nos documentos curriculares, com implicações no pensamento e na prática dos professores. Conclui-se sobre a necessidade de continuidade do debate e possíveis ações na escola, apresentando uma questão paradoxal: a prioridade da atual política de ensino médio nos auxilia ou retira a ideia de se construir o ensino médio para além de competências e conteúdos curriculares enunciados?

Palavras-chave: Ciência na Escola. Diretrizes Curriculares Nacionais. Ensino Médio. Educação Profissional. Pacto Nacional do Ensino Médio.

\begin{abstract}
The popularization of science education in school (non-hegemonic conception) aiming an increase of secondary school education's quality as a deliberate proposition by Secondary School Directorship of MEC's Secondary School and Technology Secretariat in the years 2003 and 2004, is the objective of this work, based in Ramos (2012; 2011; 2002 e 2003), Vigostsky (1989) and Marandino (2003). The result highlights that the proposal didn't advance as a structuring public policy. Through current DCNEM and Pacto Nacional pelo Ensino Médio [National Pact for the Secondary School] expectations, it is made an attempt in order to keep the importance of this debate included on curriculum documents, with implications on teachers' thinking and practices. We conclude on the necessity of the debate's continuity, and possible actions in school, presenting a paradoxal issue: the priority of secondary school current policy helps us or remove the idea about building the secondary school over and above its competencies and outlined curricular content?
\end{abstract}

Keywords: Science in School. National Curricular Guidelines. Secondary Education. Professional education. National Pact for Secondary Education.

\footnotetext{
1 Doutora em Educação pela Universidade Federal Fluminense (2001). Pós-doutora em etnossocialogia do conhecimento profissional pela Universidade de Trás-os-Montes e Auto Douro, de Portugal. Professora Adjunta da Faculdade de Educação e do Programa de Pós-Graduação em Políticas Públicas e Formação Humana da Universidade do Estado do Rio de Janeiro.
} 


\section{Introdução}

O ingresso do Partido dos Trabalhadores na gestão do Estado brasileiro, em 2003, oportunizou tentativas por parte de intelectuais e educadores que assumiram funções de gestão na estrutura do Ministério da Educação na ocasião, de rompimento com a política educacional anterior, caracterizada por um conjunto de reformas nos planos conceitual, organizacional e econômico.

Constituída por educadores do campo crítico da área de Trabalho e Educação², a Secretaria de Educação Média e Tecnológica à época - SEMTEC -, reiterou esse compromisso, porém sem o propósito de encaminhar uma nova reforma educacional a partir do aparelho de Estado e do diálogo restrito com consultores (o que foi a prática dos governos anteriores). Ao contrário, o que se pretendeu foi construir, em diálogo com a sociedade e educadores, uma nova concepção hegemônica, à luz da utopia que tanto mobilizou os debates pela nova LDB.

Um olhar sobre os anos de 2010 a 2013 nos sinalizariam ações importantes. Uma delas foi o movimento de elaboração de novas Diretrizes Curriculares Nacionais para o Ensino Médio e para a Educação Profissional, a partir de 2010, que se efetivaram em 2012 (quase dez anos após a publicação do Decreto n. 5.154/2004, que teria exigido mudanças conceituais e organizativas desde então).

Outra ação importante foi O Pacto Nacional pelo Fortalecimento do Ensino Médio, instituído pela Portaria $n^{\mathrm{o}} 1.140$, de 22 de novembro de $2013^{3}$. As ações privilegiadas inicialmente foram o redesenho curricular na perspectiva integrada (articulando as dimensões do trabalho, da ciência, da cultura e da tecnologia) a ser desenvolvida nas escolas por meio do Programa Ensino

2 Citamos, além da própria autora deste texto, a pesquisadora Ivone Moreira. Essas autoras assumiram, respectivamente, as Diretorias do Ensino Médio e da Educação Profissional na SEMTEC no início de 2003. Em 2004, com a substituição do então Ministro da Educação, Cristóvam Buarque por Tarso Genro (tendo Fernando Haddad como Secretário Executivo, que, em curto prazo, tornou-se o Ministro que mais tempo permaneceu nessa cadeira ao longo das gestões do PT), o MEC passou por uma reestruturação que incorporou o Ensino Médio à Secretaria de Educação Básica. A autora deste texto foi exonerada de seu cargo, e, tempos depois, também a Diretoria de Educação Profissional teve outra titular, devido à saída, a pedidos, da anterior. O então Secretário, Antonio Ibañez Ruiz, mantevese no cargo até 2005. Para se conhecer um pouco dos princípios que orientaram o início desta gestão da SEMTEC, sugerimos a leitura de Ramos, Moreira e Ruiz (2003).

${ }^{3}$ Conforme consta do respectivo sítio (http://pactoensinomedio.mec.gov.br/), este representaria a articulação e a coordenação de ações e estratégias entre a União e os governos estaduais e distrital na formulação e implantação de políticas para elevar o padrão de qualidade do Ensino Médio brasileiro, em suas diferentes modalidades, orientado pela perspectiva de inclusão de todos que a ele têm direito. 
Médio Inovador - ProEMI. A segunda foi a Formação Continuada de professores do Ensino Médio, cuja primeira etapa foi desencadeada no primeiro semestre de $2014^{4}$.

Propomo-nos a fazer uma reflexão sobre algumas proposições que não avançaram como política pública estruturante, mas que merecem ser conhecidas. Apresentaremos o esforço que, em 2003 e parte de 2004, a Diretoria de Ensino Médio da então SEMTEC tentou fazer, em nome da melhoria da qualidade da educação científica no ensino médio nas escolas dos sistemas estaduais de ensino, sob a mesma concepção que hoje se tenta fazer sobreviver por intermédio das atuais DCNEM e pelo suspiro do Pacto Nacional pelo Ensino Médio. A oportunidade de abordar este tema leva-nos a pensá-lo à luz da importância do debate sobre a educação científica na escola considerando as concepções de ciência presentes nos documentos curriculares, com implicações no pensamento e na prática dos professores. Concluímos perguntando-nos sobre o quanto um debate sobre o tema e possíveis ações seriam exequíveis, e se a prioridade conferida pela política de ensino médio atual à elaboração das Bases Curriculares Nacionais Comuns ajuda ou retira a referência de se pensar o ensino médio para além de competências e conteúdos curriculares.

\section{Algumas observações sobre a concepção de ciência e as políticas educacionais ${ }^{5}$}

A educação em ciências é um tema que tem merecido atenção por parte de pesquisadores e educadores, especialmente das Ciências da Natureza, normalmente reunidos em torno da área de ensino de ciências, desdobrada em ensino de química, de física, de biologia, assim por diante, juntamente com intelectuais da área da educação. As preocupações com o cumprimento da principal finalidade do processo educativo, que é a formação humana e o desenvolvimento das condições para o exercício da cidadania plena pelos sujeitos em sua vida social, leva-nos a compreender que a educação científica é uma condição necessária ao desenvolvimento da pessoa humana e ao exercício da cidadania.

\footnotetext{
${ }^{4}$ Esta contou com a colaboração de vários educadores na elaboração dos Cadernos de Formação e com a parceria entre as Secretarias Estaduais de Educação e Universidades Públicas. Disponível em http://pactoensinomedio.mec.gov.br/index.php?option=com_content\&view=category\&id=13\&Itemid=11 7 .

${ }^{5}$ As ideias que constituem os itens seguintes foram expostas originalmente no seminário sobre o tema realizado pela UFRGS, em 26/03/2004. Optamos por resgatá-las neste texto, tal como enunciamos na introdução, em benefício do registro histórico e visando ao seu debate no contexto da política atual de ensino médio, orientada pelo Pacto Nacional, considerando não termos conhecimento de sua eventual publicação na primeira oportunidade.
} 
Poderíamos discutir então a especificidade da educação em ciências relacionada a estas finalidades. Primeiro, em relação ao desenvolvimento da pessoa humana, a experiência escolar é o meio pelo qual as crianças e os jovens desenvolvem-se cognitivamente. Nesse sentido, falar em aprendizagem das ciências implica o processo pelo qual Vygotsky (1989) entende como construção de conceitos. Segundo, a educação científica, na perspectiva do exercício da cidadania, tem como pressuposto o direito de todas as pessoas de terem acesso ao conhecimento construído pela humanidade ao longo da História e ao próprio processo social de construção desse conhecimento.

No encontro de ambas as perspectivas, estão o desenvolvimento intelectual das pessoas, sob a característica teleológica do ser humano, ou seja, a mobilização de suas capacidades cognitivas motivadas por intenções concretas determinadas sócio-historicamente. É nesse sentido que, para além de aprender ciência, é preciso formar as pessoas para construir conhecimentos científicos, compreender e transformar o mundo em que se vive.

Disso, depreendemos que a educação científica na escola deve considerar a ciência em suas dimensões tanto epistemológica quanto metodológica, de forma indissociada. A primeira dimensão é o plano da concepção de mundo, do que é o real, do que é conhecimento, portanto, da própria ciência. Na segunda, está a reflexão sobre os métodos de produção de conhecimentos que guarda coerência com uma dada epistemologia.

Compreendemos a ciência numa perspectiva sócio-histórica. Ou seja, como síntese de conhecimentos produzidos e legitimados socialmente ao longo da História, resultados de um processo empreendido pela humanidade na busca da compreensão e transformação dos fenômenos naturais e sociais. Nesse sentido, a ciência conforma conceitos e métodos cuja objetividade permite a transmissão para diferentes gerações. Ao mesmo tempo, esses podem ser questionados e superados historicamente, no movimento permanente de construção de novos conhecimentos.

Assim, partimos do pressuposto de que a função real da teoria científica é penetrar a superfície empírica da realidade e captar as relações que geram as formas aparentes e sensíveis da realidade. Os conceitos teóricos da ciência não são redutíveis a conceitos observáveis, como no empirismo, nem são construções subjetivas impostas à realidade pelos teóricos, como no idealismo. Os conceitos científicos procuram apreender os aspectos não observáveis da realidade no plano do pensamento. Portanto, enquanto o pensamento busca captar a essência da realidade empírica, o conhecimento é um produto histórico construído pela práxis social (Ramos, 2003). 
Disso, advêm questões importantes sobre o método. A historicidade procura dar vida às razões, aos problemas e às dúvidas que motivaram o avanço do conhecimento. Isso não com o propósito de reproduzir esses processos, uma vez que o conceito de história preserva as especificidades sócio-culturais de cada espaço e tempo em que os fatos ocorrem, mas como forma de superar o enciclopedismo - quando conceitos históricos são transformados em dogmas - e o espontaneísmo e empirismo, forma acrítica de apropriação dos fenômenos, que pode não ultrapassar o senso comum (Ramos, 2001).

Assim, diferentemente das teses dos pragmatistas, que têm na experiência a primazia do pensamento reflexivo, para Vygotsky, a consciência reflexiva chega aos estudantes pelos portais dos conceitos científicos. Fica evidente, então, que o fato de a experimentação ter significativa importância na aprendizagem científica não implica que essas devam ter, necessariamente, preeminência aos conceitos. Ao contrario, a apreensão e a construção dos conceitos científicos que fundamentam essas práticas são condições sine qua non para a compreensão dos eventos e para as proposições criativas sobre o que se experiência (Ramos, 2002).

Sob esses pressupostos é que temos feito a crítica às concepções hegemônicas de ciência, de um lado, centrada no positivismo - herdeira da racionalidade mecaniscista - e, de outro lado, aquela que tem por base o pragmatismo e o (neo) pragmatismo, que têm expressado certo relativismo do conhecimento. Por esse enfoque, todo conhecimento é igualmente válido, desde que se mostre útil para o sujeito. Se, no primeiro sentido, o real só pode ser apreendido mediante métodos controlados e replicáveis, no segundo, o real é o que a experiência sensível permite captar.

O positivismo científico até hoje se reproduz na pedagogia tecnicista. A pedagogia das competências, por sua vez, como temos demonstrado, fundamenta-se no pragmatismo e tem convergido com concepções pós-modernas que legitimam a referida visão relativa do conhecimento - o que radicalmente distinto do seu caráter histórico ${ }^{6}$.

\footnotetext{
${ }^{6}$ Essa discussão apresenta-se de forma mais aprofundada nos artigos RAMOS, Marise N. A educação profissional pela Pedagogia das Competências: para além dos documentos oficiais. Educação e Sociedade, vol. 23, n. 80, setembro/2002, p. 405-427 e RAMOS, Marise N. É possível uma Pedagogia das Competências contra-hegemônica? Relações entre pedagogia das competências, construtivismo e neopragmatismo. Trabalho, Educação e Saúde. Vol. 1, n. 1, março/2003, p. $115-130$.
} 
Tentativas (inconclusas) de elaboração de uma política de educação em ciências no ensino médio em 2003

Ainda que não hegemônica no pensamento educacional brasileiro, as atuais DCN EM, enunciam a relação entre trabalho, ciência, cultura e tecnologia como orientadoras do currículo do ensino médio. Não obstante, a realidade concreta da escola brasileira ainda está muito distante desses princípios e pouco tem acumulado uma discussão sobre esse tema. Os currículos, normalmente, não expressam uma concepção de ciência discutida entre os professores, mas tende a ser definido em função das condições objetivas da escola ou à sua revelia.

Porém, face ao acúmulo de conhecimento nesse campo, produzido por universidades, instituições de pesquisa, sociedades acadêmicas, escolas, dentre outros, e, ainda, devido à complexidade e profundidade do tema, enquanto estivemos no exercício da Diretoria de Ensino da Secretaria de Educação Média e Tecnológica do Ministério da Educação, iniciamos um diálogo com um conjunto de instituições ${ }^{7}$ em torno de três eixos: formação de professores; currículo e ensino; e divulgação e popularização da ciência. A partir desse diálogo, partimos para o desenvolvimento de um Plano de Educação em Ciências. Por ocasião do lançamento desse Plano ${ }^{8}$, foi assinado um protocolo de cooperação com o Ministério da Ciência e Tecnologia, base para o desenvolvimento conjunto de um projeto intitulado Ciência de Todos 9 .

O Plano de Educação em Ciências no Ensino Médio: o que poderia ser um pequeno avanço O que à época denominados de Plano de Educação em Ciências no Ensino Médio, seria a articulação de diversas ações em torno de um mesmo objetivo: melhorar a qualidade do ensino de ciências nas escolas e incorporar a prática e a reflexão científicas na vida escolar e social de estudantes de ensino médio. Este plano apresentava ações em torno de quatro grandes eixos: formação de professores; diretrizes curriculares; ampliação do acesso e melhoria da qualidade de materiais didáticos; articulação com a política de divulgação científica.

\footnotetext{
7 A primeira reunião ocorreu em 03/04/2003, contando com a presença das seguintes representações: Academia Brasileira de Ciências (ABC), UNESCO, Coordenação de Aperfeiçoamento de Pessoal Docente (CAPES/MEC), Conselho Nacional de Pesquisa (CNPq/MCT), Fundação Oswaldo Cruz (FIOCRUZ), Instituições Federais de Educação Tecnológica (IFETs), Sociedade Brasileira para o Progresso da Ciência (SBPC) e Colégio Pedro II.

${ }^{8}$ Lançado em 05/08/2003, em Brasília, numa solenidade intitulada "Professor em Cena".

${ }^{9}$ Objeto de muitas negociações entre os Ministérios parceiros e desses com as sociedades científicas, este plano acabou não sendo colocado em prática.
} 
Os seguintes objetivos foram delineados visando à melhoria da formação de professores: a) ampliar e melhorar a formação inicial de professores de ciências, mediante incentivo com bolsas de licenciaturas e abertura de campos de estágio orientado; b) promover a formação continuada de professores de ciências, mediante cooperação institucional, com apoio da Capes, do CNPq e de outros órgãos de fomento e coordenada por uma comissão de aperfeiçoamento de professores de ensino médio; c) incentivar projetos curriculares voltados para a educação científica e mudanças curriculares que incorporem abordagens práticas, problematizadoras e históricas das ciências. Uma comissão de aperfeiçoamento de professores de ensino médio foi instituída pela Portaria no 3707, de 11/12/2003, sendo composta por representantes de órgãos de governo e de entidades acadêmicas, com a finalidade de acompanhar e auxiliar a implementação das ações de formação de professores previstas no PPA 2004-2007.

Uma ação agregada às anteriores foi o apoio às reuniões regionais realizadas pela Sociedade Brasileira para o Progresso da Ciência - SBPC, considerando o potencial das sociedades científicas de difundir o conhecimento científico e contribuir para a formação de professores. Como incentivo a projetos curriculares voltados para a educação científica e mudanças curriculares foi instituído o Prêmio Grupo Ciência, com o objetivo de incentivar os professores de ensino médio das redes públicas estaduais a elaborarem e desenvolverem projetos científicos com seus alunos ${ }^{10}$. Como contrapartida os professores seriam comprometidos com a continuidade, ampliação ou desdobramento do projeto aprovado, utilizando os recursos recebidos exclusivamente nesses procedimentos. O propósito incluiu também a articulação com as instituições de ensino superior visando à orientação aos projetos. As edições do Prêmio Grupo Ciências seriam articuladas com a realização de feiras e mostras de ciências, assim como seria desenvolvida uma política de publicação para a difusão desses trabalhos.

\section{Tentativas de construção da política curricular com a sociedade}

Essas questões nos levaram, em 2003, a partir da Diretoria de Ensino Médio da então Secretaria de Educação Média e Tecnológica, a fomentar um debate sobre currículo mais

\footnotetext{
${ }^{10} \mathrm{Na}$ única edição deste prémio, em 2003, foram inscritos 106 (cento e seis) projetos. Destes, foram premiados 27 (vinte e sete) projetos estaduais (um por estado), com R $\$ 20.000,00$ (vinte mil reais) cada, e 3 (três) nacionais, com $\mathrm{R} \$$ 30.000,00 (trinta mil reais) cada, totalizando $\mathrm{R} \$$ 630.000,00 (seiscentos e trinta mil reais). 
diretamente com as sociedades científicas das diversas áreas de conhecimento, reunindo-nos num Fórum Permanente sobre Currículo do Ensino Médio. A aproximação dos estudiosos da área das Ciências da Natureza e de Ciências Humanas e Sociais, além das Linguagens, buscou guardar coerência com o projeto de ensino médio unitário. Este projeto, conquanto não elidisse as singularidades dos grupos sociais, constituir-se-ia como síntese do diverso, tendo a relação entre a ciência, cultura e trabalho como princípios estruturantes do currículo.

Nesse sentido, o estudo da Filosofia e da Sociologia e dessas em relação ao desenvolvimento da ciência moderna seria fundamental. Sabe-se que, no ensino médio, normalmente o conhecimento científico é valorizado pelo seu conteúdo em si ou pelo seu potencial econômico-produtivo. Com a ajuda da Filosofia e da Sociologia, eles poderiam ser estudados como momentos históricos, como relações políticas e sociais concretas. Esses estudos são mediações necessárias na formação dos educandos no sentido de capacitá-los teórica e metodologicamente para intervir de forma efetiva, ativa, crítica e consequente em seu meio social.

O trabalho do Fórum Permanente sobre Currículo no Ensino Médio envolveria, dentre outros objetivos, procurar conhecer como as escolas e os educadores compreendiam e apreendiam os documentos curriculares e as implicações trazidas para a prática pedagógica, para a formação docente e para a qualidade do ensino; analisar e debater os princípios difundidos pelos documentos, contribuindo para que os educadores desenvolvessem a crítica em relação aos diversos documentos que recebem, desde os documentos oficiais até livros, revistas e materiais didáticos em geral, de modo que eles fizessem seus próprios julgamentos, individual e coletivamente e realizassem suas escolhas de forma consciente; discutir com os educadores outras concepções pedagógicas, em relação às quais eles pudessem também se posicionar e fazer escolhas; manter um permanente diálogo entre escolas, educadores, instituições de ensino e pesquisa, de tal modo que as concepções pedagógicas fossem conhecidas, analisadas, debatidas e difundidas a partir da realidade concreta vivida e construída no cotidiano escolar.

A proposta implicou ainda o planejamento de encontros estaduais e regionais, organizados a partir da participação das escolas no concurso ao prêmio Grupo Ciência, com o objetivo de proporcionar a difusão das práticas dos educadores, mediante um processo em que essas práticas sejam analisadas e debatidas por especialistas, por outros educadores, etc., construindo-se, assim, uma práxis coletiva 


\section{Ampliação do acesso e melhoria da qualidade de materiais didáticos}

Afirmamos que o currículo deve assentar-se sobre uma base epistemológica na qual se firmam também as opções metodológicas. Se os métodos contribuem para estruturar o processo pelo qual se desenvolve o ensino e a aprendizagem, os materiais didáticos são mediações na relação do professor com o conhecimento, daquele com os alunos e dos alunos com o conhecimento. As diretrizes curriculares nacionais para o ensino médio - tanto as revogadas quanto as atuais destacaram o princípio da contextualização como processo de enraizamento dos conceitos científicos na realidade vivenciada pelos alunos, para produzir aprendizagens significativas. Isso significa partir dos fenômenos conhecidos pelos estudantes em direção aos conhecimentos formais. Essa abordagem surge em oposição à transmissão dos conteúdos exclusivamente a partir das disciplinas, sem relações com a prática social.

Não obstante, é preciso considerar que os conhecimentos escolares, conquanto devam superar os conhecimentos cotidianos, não se confundem com os conhecimentos científicos, nem os reproduzem no ambiente escolar. De um lado, diante de um problema, o conhecimento cotidiano está orientado para a necessidade de resolvê-lo na prática e não para a explicação de suas razões ou para a compreensão dos princípios que o definem, podendo estar distanciado significativamente do conhecimento científico. Por outro lado, como ensinar ciências partindo-se diretamente das disciplinas científicas se o contexto e as motivações de produção dessas e de seus conceitos é distinto do que caracteriza a escola; se os problemas propostos num e noutro também são diferentes?

$\mathrm{Na}$ sua forma habitual, os problemas escolares, muitas vezes, consideram tacitamente que o aluno já está na margem da ciência, que esta desperta o seu interesse e que ele quer resolver problemas científicos. Para um aluno que não se interessa pela ciência, que não se sente sintonizado com o seu discurso e suas maneiras de agir, os problemas escolares costumam representar atividades artificiosas. Por isso, a pertinência de se partir do contexto de vivência do aluno. Entretanto, quando se parte do contexto de vivência do aluno, enfrentam-se concepções prévias, normalmente constituídas de representações errôneas ou limitadas quanto à explicação da realidade. Mesmo sendo um importante meio de estimular a curiosidade do aluno, ampliando e aprofundando seus conhecimentos, a pertinência de um processo de ensino-aprendizagem contextualizado está condicionada à possibilidade de levar o aluno a ter consciência sobre seus 
modelos de explicação e compreensão da realidade, reconhecê-los como equivocados ou limitados, enfrentar o questionamento e colocá-los em cheque num processo de desconstrução de conceitos e reconstrução/apropriação de outros. Por isso, uma das contradições dos materiais didáticos está em tentar transmitir e sistematizar o conhecimento científico de forma didática, distanciando-o, então, tanto de seu contexto de produção científica, quanto do contexto de vivência dos alunos.

Assim, uma importante contradição foi enfrentada tanto pelos dirigentes do Ministério da Educação à época, quanto pelos educadores, especialmente na definição de critérios de qualidade dos livros didáticos e na avaliação das obras. Trata-se do fato de, mesmo considerando a legalidade, a legitimidade e a importância da pluralidade pedagógica, a definição de critérios para a avaliação das obras didáticas terminam por impor à produção editorial parâmetros estabelecidos, seja pelo próprio Ministério, caso já se os tenham por base; seja pelas equipes avaliadoras, que, de alguma forma, farão prevalecer suas concepções pedagógicas. Dessa forma, uma política de livro didático sempre estará relacionada, mais ou menos intensamente, a uma política de currículo nacional, fortemente questionada pela área, especialmente quando a dimensão cultural do currículo é considerada. Parece-nos que a superação dessa contradição só poderia ocorrer na medida em que a avaliação dos livros didáticos não fosse feita pelo Ministério da Educação, mas sim pelos próprios professores.

\section{Articulação com a política de divulgação científica}

Realizar a articulação da política de educação em ciências com a de divulgação científica foi o propósito do protocolo de cooperação firmado entre o Ministério da Ciência e Tecnologia e o Ministério da Educação em 05 de agosto de 2003. O objetivo dessa articulação foi a melhoria da formação científica e a popularização da ciência na sociedade. A implementação do objetivo previsto nesse protocolo deu-se mediante a tentativa de elaboração do projeto Ciência de Todos. Este projeto identificava duas vertentes para ampliar e melhorar a qualidade do conhecimento científico da população, contribuindo para a alfabetização científica da sociedade, a saber: a) disponibilizar mais recursos didático-pedagógicos e qualificar os professores da rede formal de ensino; e b) criar, promover e estimular fortemente centros de popularização do conhecimento científicos em nível não formal. 
Essas vertentes foram caracterizadas, respectivamente, como Ciência na Escola e Ciência na Sociedade. A vertente Ciência na Escola pretendia oferecer aos docentes oportunidades para aprofundar seus conhecimentos, bem como implantar ou aprimorar o uso dos laboratórios de ciências nas escolas, fortalecendo o ensino nas escolas das redes públicas brasileiras. A vertente Ciência na Sociedade, por sua vez, visava contribuir para difusão de conhecimentos científicos e tecnológicos necessários para a melhoraria da qualidade de vida, facilitando o acesso da sociedade ao saber científico. Com base nisso, o programa teria um componente de formação de professores; outro de instalação de laboratórios e recursos da tecnologia da informação na escolas; um terceiro, de fortalecimento de espaços de apoio às escolas e à difusão e popularização da ciência e tecnologia, pelo qual se buscaria forte relação entre os espaços formais de educação em ciências (as escolas) e os não formais (museus e centros de ciências); e, por último, um componente de difusão científica.

A proposta de instalação de laboratórios e recursos da tecnologia da informação nas escolas foi eivada de polêmicas. Primeiramente, uma forte crítica se fez sentir a partir das sociedades científicas, especialmente aquelas que já desenvolviam projetos de formação de professores, no sentido de não se recair no mito do experimentalismo, desvinculado da realidade da escola, dos professores e dos alunos. Em outras palavras, não se pode considerar suficiente que as escolas estejam bem equipadas com laboratórios, de acordo com um padrão determinado externamente a elas, se a necessidade não parte dos próprios professores em razão da sua formação e de seus interesses e condições para inovar sua prática pedagógica.

Uma importante discussão se fez, então, sobre a relação entre a escola formal e espaços não formais de educação em ciências, como os centros e museus de ciências. Marandino (2003), por exemplo, ao constatar que as formas e estratégias pela qual a divulgação científica vem se dando fora do espaço escolar, e, nesse sentido, sobre como a pesquisa na área de educação em ciências extra-escolar vem crescendo, defende a parceria entre universidades, museus e centros de ciências e escolas no processo de alfabetização científica dos cidadãos $^{11}$, entendida como partilha do poder

\footnotetext{
${ }^{11}$ A autora que estamos citando adverte utilizar o conceito de alfabetização científica a partir das discussões sobre letramento. Nesse sentido, "ser letrado cientificamente significa não só saber ler e escrever sobre ciência, mas cultivar e exercer as práticas sociais envolvidas com a ciência” (idem, p. 63). Attico Chassot (2001), de forma objetiva, considera a alfabetização científica como o conjunto de conhecimentos que facilitariam aos homens e mulheres fazer uma leitura do mundo onde vivem. Para ele, seria desejável que os alfabetizados cientificamente não apenas tivessem 
e da responsabilidade de formar e educar. A principal preocupação quanto ao propósito do programa em fortalecer espaços de apoio às escolas e à difusão e popularização da ciência e tecnologia, considerando que esses espaços poderiam ser os centros e museus de ciências, esteve em não escolarizar esses espaços nem utilizá-los como solução para as dificuldades que os sistemas de ensino possuem de organizar ambientes para o ensino e a aprendizagem científicas. A frequência de professores e alunos a esses espaços não poderia se confundir com uma medida de substituição à falta de professores e à precariedade de ambientes e recursos didáticos nas escolas.

O conceito de parceria, portanto, implicaria fazer com que os partícipes conhecessem e compreendam a dinâmica e as características próprias de cada um dos espaços, para que professores da educação básica pudessem relacionar essas experiências com seus interesses e necessidades no âmbito do ensino formal e os centros e museus de ciências percebessem sua utilidade social. Assim, poderiam valer-se do conhecimento em educação para melhor organizar suas atividades na relação com as escolas.

Nas palavras de Sepúlveda (apud Marandino, idem, p. 64), “é imprescindível levantar o debate sobre a natureza do saber que se pode e se quer apresentar nos museus, sobre as características da aprendizagem nestas instituições, sobre as relações a serem desenvolvidas com o ensino formal”. Essas questões mereceriam ainda muita atenção, ampliando o campo de confluência da educação formal e não formal naquilo que potencialmente a parceria poderia promover de renovação de saberes e de melhoria e ampliação da educação científica dos jovens.

\section{Considerações finais}

Tal como sinalizamos na introdução deste texto, atualmente a política nacional da educação básica em geral, com implicações diretas sobre o ensino médio, está centrada na consulta pública sobre a Base Nacional Curricular Comum ${ }^{12}$. O documento organiza o currículo das etapas da educação básica, especialmente os ensinos fundamental e médio, nas Áreas Curriculares e respectivos Componentes, para os quais são indicadas Unidades de Aprendizagem. Estas, por sua vez, se constituem por Conhecimentos Conceituais; Contextualização Histórica, Social e Cultural;

facilitada a leitura do mundo em que vivem, mas entendessem as necessidades de transformá-lo, e transformá-lo para melhor.

12 Disponível em: http://basenacionalcomum.mec.gov.br/\#/site/biblioteca. Consulta em 01/02/2016. 
e Processos e Práticas de Investigação. Cada um desses apresentarão um conjunto de Objetivos de Aprendizagem. Lê-se, no documento, que esses se definem "pela articulação entre a singularidade das áreas de conhecimento e de seus componentes e as especificidades dos estudantes ao longo da educação básica". (BRASIL. MEC et. al., 2015, p. 11).

Sem pretendermos fazer uma análise dessa proposta, o que já ocorre por estudiosos do campo do currículo - inclusive questionando sua necessidade e/ou pertinência - além dos diversos docentes envolvidos com sua discussão, limitamo-nos, nesse momento, a algumas impressões. Primeiramente, parece-nos que currículos sob esta referência proporcionariam aos estudantes uma boa formação, entretanto nos limites que o próprio documento anuncia, a saber: "uma formação guiada por princípios de liberdade e por ideais de solidariedade humana, que inspire o exercício pleno da cidadania, promova a inserção no trabalho e incentive a continuidade dos estudos" (idem, p. 184).

Trata-se, pois, de princípios de fundo liberal, posto que numa sociedade de classes a liberdade é de cunho formal e a solidariedade não leva à eliminação de desigualdades. Desse modo, o exercício da cidadania não pode ser pleno, salvo como promessa, uma vez que é demarcada por direitos exclusivamente formais, dos quais nem todos necessariamente se valem. Do mesmo modo, a inserção no trabalho e a continuidade dos estudos não são determinadas somente por uma boa formação escolar, mas sim por relações socioeconômicas que vão além desta.

Tendo sido elaborado predominantemente nos espaços oficiais de governos e posteriormente dado a conhecer à sociedade, de imediato transparece a marca de poder no documento. O princípio da historicidade do conhecimento é completamente substituído pelo de contextualização, da mesma forma que o caráter interventivo social e politicamente interessado que estariam presentes numa concepção de histórico-dialética de ciência é substituído pela aplicabilidade pragmática. Pouca chance nos parece haver para que as comunidades escolares construam seus currículos considerando suas singularidades e as respectivas relações com as particularidades históricas dos fenômenos científicos, tecnológicos, culturais e sociais estudados, bem como as mediações que nos permitem compreender o modo de produção capitalista como uma totalidade social.

Por tais razões, parece-nos que a abordagem seguida, por manter uma lógica pragmática, contribui pouco para levar os estudantes a compreenderem o caráter não neutro do conhecimento 
científico, para o qual as perspectivas da historicidade e da totalidade são fundamentais. Em outras palavras, o documento não parece interessado em fazer com que o processo de ensinoaprendizagem leve os estudantes a compreenderem os problemas, as motivações, as disputas e as relações de classe mediante as quais os conhecimentos são produzidos e validados como científicos.

Sendo assim, a BNCC, em nossa visão, parece convergir mais com uma epistemologia pragmática que fundamenta a Pedagogia das Competências, do que com a histórico-dialética sobre a qual se sustentam os princípios da educação politécnica e educativo do trabalho, os quais inspiraram, mesmo de forma híbrida e contraditória - repetimos - as atuais DCNEM. Um paralelo entre as nomenclaturas da BNCC e das DCNEM revogadas e dos PCN que a essas se seguiram pode ser tomado como um exemplo de sua referência epistemológica hegemônica: no lugar de Competências, têm-se os Objetivos de Aprendizagem, ambos centrados no estudante e com o mesmo tipo de enunciado que remete à ação cognitiva e/ou operacional, ou seja, a preeminência do psicológico sobre o lógico; no lugar de Bases Científicas - os conhecimentos que seriam insumos para o desenvolvimento das enunciadas competências - Conhecimentos Conceituais; no lugar de Bases Tecnológicas - igualmente, conhecimento aplicado insumo para a aprendizagem e uso das tecnologias -Processos e Práticas de Investigação. Em síntese, se não podemos afirmar sermos contrários à existência de uma $\mathrm{BNCC}$, reiteramos que esta, tal como se apresenta, no caso do ensino médio, pode levar ao enfraquecimento e ao esquecimento das atuais DCNEM.

Essas diretrizes, por sua vez, foram discutidas na tentativa de se ir ao encontro de interesses e necessidades de jovens e adultos da classe trabalhadora, tendo o trabalho nos seus sentidos ontológico e histórico como princípio educativo. Pelo documento em debate, a tendência pode ser o ensino centrado em competências e habilidades que seriam requeridas dos jovens a partir de um parâmetro externamente elaborados a eles e que se centram nos comportamentos requeridos para um mundo instável em que as desigualdades são, no máximo, controladas, mas não superadas.

Em tensão com esta tendência, as contribuições que tentamos trazer neste texto têm o propósito de chamar a atenção para a necessidade e a possibilidade de se desenvolver uma política pública de educação com outros referenciais. Nesse sentido, as divergências que atravessam o debate, especialmente dependendo do ponto de vista pelo qual se analisa o problema, devem se constituir em oportunidades para se construir uma concepção sobre a educação em geral e científica 
em particular que, conquanto não agregue o consenso, possibilita o permanente debate entre as distintas concepções, evitando-se, assim, a adequação a um suposto "pensamento único".

Fundamentalmente, defende-se que conteúdo e método não se separam, assim como ambos não existem a despeito de um projeto de sociedade e de propósitos mais amplos em termos da formação humana e social. A discussão efetiva entre sociedade política e sociedade civil - com prioridade dos educadores e comunidades escolares - continua a ser perseguida. Perceber e disputar esta possibilidade implica, ao mesmo tempo, evidenciar as diferenças de interesse entre as diferentes classes e frações de classe que constituem esses segmentos.

\section{Referências}

CHASSOT, A. Alfabetização científica: questões e desafios para a educação. Ijuí. Ed. Unijuí, 2001.

MAGALHÃES, J. Os professores e a alfabetização: saberes docentes no entrecruzamento de experiências, práticas e teorias (Dissertação de Mestrado). Programa de Pós-Graduação em Políticas Públicas e Formação Humana UERJ, 2014.

MARANDINO, M. A formação inicial de professores e os museus de ciências. In: SELLES, S. e

FERREIRA, M. Formação Docente em Ciências, pp. 59-78. Rio de Janeiro, EDUFF, 2003.

RAMOS, M. N. A educação profissional pela Pedagogia das Competências: para além da superfície dos documentos oficiais. Educação e Sociedade, v. 23, n. 80, Campinas, pp. 405-427, set. 2002.

É possível uma Pedagogia das Competência contra-hegemônica? Relações entre pedagogia das competências, construtivismo e neopragmatismo. Trabalho, Educação e Saúde, v.1, n. 1, Rio de Janeiro, pp. 93-114, março de 2003.

O currículo para o ensino médio em suas diferentes modalidades: concepções, propostas e problemas. Educação \& Sociedade (Impresso), v. 32, p. 771- 788, 2011.

RAMOS, M. N.; MOREIRA, Ivone ; IBAÑEZ, Antonio. A educação do trabalhador: políticas articuladas de educação básica e profissional. Movimento, Niterói - RJ, n.8, p. 11-22, 2003. 
RAMOS, M. N. (Org.); FRIGOTTO, Gaudêncio (Org.); CIAVATTA, Maria (Org.). Ensino Médio

Integrado: Concepção e Contradições. 1. ed. São Paulo: Cortez, 2005.

RAMOS, M. N.; CIAVATTA, Maria. A "era das diretrizes": a disputa pelo projeto de educação dos mais pobres. Revista Brasileira de Educação (Impresso), v. 17, p. 11-37, 2012.

VYGOTSKY, L. S. Pensamento e Linguagem. São Paulo, Martins Fontes, 1989. 